\title{
Anežka Schulzová as a Theatre Critic
}

\author{
Michal Fránek
}

In the Czech cultural milieu Anežka Schulzová (1868-1905) is known above all as Zdeněk Fibich's girlfriend and as the author of his last three operas. ${ }^{1}$ That is why all her other literary activities (including ground-breaking translations, literary studies and profiles, and above all her "insightful theatre articles"2 published especially between the end of the 1880s and mid-1890s) stay in the shadow. This period was characterised by the emergence of a young, artistically strong generation of writers, by fights for realism and naturalism in literature as well as at the theatre, and at the same time new artistic movements were asserted. In this milieu criticism played an important role because it established itself as a discipline equal to artistic production. Anežka Schulzová entered into this context with her critiques.

Most of her theatre critiques were published from 1888 on in the weekly Zlatá Praha [Golden Prague], ${ }^{3}$ which was a popular-scientific journal aimed at fiction and which was edited by her father, Ferdinand Schulz; from 1889 Schulzová's critiques were published in a similar (monthly) periodical Květy [Flowers]. ${ }^{4}$ Both journals were addressed to a broader

1 Jiři Kopecký, Opery Zdeňka Fibicha z devadesátých let 19. století [The Operas of Zdeněk Fibich from the 1890s] (Olomouc, 2008), p. 76-93. I would like to thank Jiří Kopecký for his help with this study.

2 Arne Novák, Jan V. Novák, Přehledné dějiny literatury české od nejstař̌ich dob až po našse dny [A General History of Czech Literature from Antiquity to the Present] (Brno, 1995), p. 1073.

3 The first article signed by the code $\alpha$-an informal article on Šibřinky-was published on 24 February 1888, followed by the review of the Poetry Collection Dumy a legendy [Dumas and Legends] by Otakar Mokrý on 27 February 1888. In the autumn (on 12 October 1888) she published her first theatre article-a review of Praktikus by F. A. Subert. Vladimír Hudec incorrectly alleges that her review of Noc na Karlštejně [A Night at Karlštejn] by Vrchlický was the first of her critiques (Vladimír Hudec, Zdeněk Fibich /Prague, 1971/, p. 114).

4 Reviews in these journals were published in the section 'From the National Theatre' [Z Národního divadla]. 
readership ${ }^{5}$ and that is why there was not enough space devoted to theatre issues-on the other hand it could speak to more readers and influence their tastes. Schulzová was aware of this potential and she put all her effort into popularizing works she considered as high-brow literature. Her critiques were mostly focused on a detailed description of the plot; however, they never lacked evaluation and she usually put the works into a literary or broader cultural context. The critiques written for both periodicals were usually devoted to the same plays, although the journal Květy provided her with more space for profound analyses.

Schulzová's attitude towards classic repertoire (e.g. Shakespeare, Zlatá Praha 21 December 1888) in the National Theatre was very warm because she considered it a touchstone of every actor and director. Similarly she understood classical dramas. In order to explain the atmosphere in classical tragedy to readers, she described in detail the plot of Antigone by Sophocles-"the top of Classical drama"-or the plot of Oedipus the King (Zlatá Praha 29 November 1889). She admitted her initial hesitation and curiosity when she went to see the comedy Manaechmi by Plautus. Both feelings were mainly caused by misgivings about whether such a play, more than 2000 years old, could attract the attention of a modern audience. She eventually endorsed the eternal lifetime of this play (Zlatá Praha 10 October 1890). Similarly she evaluated El villano en su rincón by Lope de Vega (Zlatá Praha 21 March 1890), Tartuffe by Molière (Zlatá Praha 26 February 1892), The Cid by Corneille (Zlatá Praha 22 September 1893) or The Mistress of the Inn by Goldoni (Zlatá Praha 7 April 1893). She was more critical towards works by Friedrich Schiller. His play The Robbers was described above all as a work of historical-literary value which could no longer speak to a modern audience (Zlatá Praha 31 October 1890, Kvéty 1 December 1890). On the other hand she appreciated Mary Stuart highly and sharply reproached the National Theatre's insensitive cuts (Zlatá Praha 10 April 1891). She held a similar attitude towards Egmont by Goethe, which she did not count among the best playwrights' works and which-according to her-could only elicit a cold admiration (Zlatá Praha 15 January 1892).

In contemporary repertoire Schulzová was very critical of French drama that formed an essential part of works played at the National Theatre. She reproached conventional plots, such as the common topic of infidelity: "French playwrights cannot do without infidelity; infidelity is the crucial element of their creativity, and when needed, they add other elements." " Her irritation was not only moral, it was above all artistic. For similar reasons she refused to acknowledge the works of Victorien Sardou which were very successful in the period. She reproached his affectation, calculation and deceitfulness of main characters. On the other hand even Schulzová was enchanted by the perfect dramatic

5 Stanislava Mazáčová, Zdeněk Pešat, "Zlatá Praha”, in: Luboš Merhaut (ed.), Lexikon české literatury [A Lexicon of Czech Literature], Vol. 4/II (Prague, 2008), p. 1764-1769. Jiřina Táborská, "Květy”, in: Vladimír Forst (ed.), Lexikon české literatury, vol. 2/II (Prague, 1993), p. 1095-1102.

6 Anežka Schulzová, “Z Národního divadla. Sofokles: Antigona”, Zlatá Praha, 6 (1889), p. 107.

7 Anežka Schulzová, "Z Národního divadla. Armand d’Artois: Aféra Clémenceaeova”, Zlatá Praha, 6 (1889), p. 167. 
skill in contriving plots, which is obvious from her review of Dora by Sardou (Zlatá Praha 24 January 1890). Similarly she ignored French comedies and farces, but at the same time she distinguished between good and bad works; she appreciated The Mouse by Pailleron (Zlatá Praha 7 December 1888).

What qualities she did appreciate in French drama she pointed out in her opinion of the comedy Frou Frou by Meilhac and Halévy: “There is something-an artistic simplicity and brightness, a naturalness in composition and a sharp style of observation, a soft irony and real emotions-which makes this comedy much better than the average fashionable plays from Paris." ${ }^{8}$ Schulzová was very well aware of the economic reasons which made the National Theatre perform plays attractive for the audience, such as comedies and exquisitely staged plays for the summer season. Nevertheless, she asked for taste and moderation in all circumstances. Sometimes she did not hide her irony when addressing the National Theatre. In her opinion the management of the National Theatre chose foreign low-brow works for patriotic reasons: "There is nothing more to be done than bow to the smooth tact of the National Theatre as to how to make the audience respect domestic plays. They have chosen such worthless and weak plays that our audience can no longer be interested in other plays from abroad." 9

Similarly she held a very critical attitude towards German drama, and again because of a dramaturgy which was not able to choose good works. According to Schulzová German farces in particular were even more boring than French ones because they lacked French wit and charm (Zlatá Praha 27 June 1890). On the other hand she thought highly of plays by Hermann Sudermann, which were played shortly after their German openings. She regarded both Honour (Zlatá Praha 6 February 1891, Květy 1 March 1891) and Homeland (Zlatá Praha 2 June 1893) in a positive light. Her concern for this playwright was so strong that she wrote an elaborate study on a new drama by Sudermann called Sodom's End in the journal Květy, even though it was not played at the theatre (Kvetty 1 October 1891). The main character in Sodom's End-a painter Willy-reminded her of the character Oscar from Ghosts by Ibsen (ibid.). She also thought highly of The Assumption of Hannele by Gerhart Hauptmann (Zlatá Praha 23 February 1894). Schulzová considered this playwright to be the most interesting personality in modern German literature. She characterised his work as a synthesis of Zola and Ibsen, connecting the better traits of these two writers (1 April 1894).

Schulzová paid close attention to Scandinavian playwrights, ${ }^{10}$ to Henrik Ibsen ${ }^{11}$ in particular. His play A Doll's House was in her opinion the most interesting work played in the

\footnotetext{
Anežka Schulzová, “Z Národního divadla. Ludovic Halévy: Frou-Frou”, Zlatá Praha, 11 (1894), p. 574-575.

9 Anežka Schulzová, "Z Národního divadla. Alfred Duruy a Henry Chivot: Madame Spinetti. Kanajev: Škola pohostinstvi”, Zlatá Praha, 7 (1889), p. 72.

10 Her concern for Scandinavians was partly caused by her admiration of the Danish literary historian Georg Brandes whose works she translated into Czech for the first time.

11 Schulzová translated from Danish into Czech the study on Henrik Ibsen by Georg Brandes and it was published between 26 February and 8 April 1892 in the journal Zlatá Praha.
} 
National Theatre for some time (Zlatá Praha 10 May 1889). She did not really agree with the ending of the play because Nora's departure from the family looked disordered: "This upsetting impression is caused by the fact that Nora-for such a selfless character-did not fulfil her duties. She was no longer bonded to a man but she was above all a mother, which means certain duties-and there are no apologies for her decision." 12

Another extended article was devoted to An Enemy of the People and in its introduction she tried to make clear Ibsen's attitude to the art of drama: "He does not put and does not want to put the core of his works into the artistic or dramatic parts. He is above all a thinker, a genius reformer of society. His main intentions are not to create artistic works but to gain supporters for his ideas and reforms." ${ }^{13}$ Schulzová also regarded the works by Bjørnstjerne Bjørnson as being more optimistic than Ibsen when writing the review of his Bankrupt: "The latest view by Ibsen of mankind leads to the opinion that people are silly because they are bad; while Bjoernson believes that they are bad because they are weak and that is why he does not judge them-he wants to help them." ${ }^{14}$

Schulzová was very critical of Russian drama but again for the same reasons: for a dramaturgy that chose below-average works characterised by a stereotypical approach and by the pursuit of effect. In her view Russian dramas lost their main function, i.e. naturalness and truthfulness which could stand against over-combined French plays (Zlatá Praha 21 December 1888). She accepted some plays with sympathy, such as The Bear's Proposal by Krylov (Zlatá Praha 3 May 1889) and she refused others because of their gutsy form which insulted her sensibility, e.g. The Marriage Proposal by Chekhov: "Another piece of real Russian leather! Stiff, hard and angular-by the time you have heard it, you will have calluses on your soul. The core is really humorous-but the whole impression is very harsh!" ${ }^{15}$ Schulzová also praised Gogol's The Government Inspector although she considered this play as a little out of date (Zlatá Praha 30 October 1891).

Schulzová observed Czech plays very carefully. She regarded older Czech plays with sympathy (Hadrián z Římsů [Hadrián from Cornice] by Klicpera, Zlatá Praha 2 December 1892) or with a benevolent superiority (Měštané a studentíci aneb Dobývání Prahy od Švédů [Citizens and Students or the Capturing of Prague by Swedes] by Tyl, Zlatá Praha 2 October 1891).

From the contemporary generation Schulzová appreciated František Věnceslav Jeřábek, Služebník svého pána [The Servant of His Lord] in particular (8 March 1889); the play Cesty verejného mínění [The Ways of Public Opinion] was characterised as a little old-fashioned but still vivid (Zlatá Praha 22 January 1892). Schulzová also regarded Jedenácté přikázání [The Eleventh Commandment] by František Ferdinand Šamberk as an important part of the Czech repertoire (Zlatá Praha 9 December 1892). Her regard

\footnotetext{
12 Anežka Schulzová, “Z Národního divadla. Činohra”, Květy, 11 (1889), Vol. I, p. 753.

13 Anežka Schulzová, “Z Národního divadla. Činohra”, Květy, 13 (1891), Vol. I, p. 750.

14 Anežka Schulzová, “Z Národního divadla. Bjørnsterne Bjørnson: Bankrot”, Zlatá Praha, 9 (1892), p. 623 .

15 Anežka Schulzová, “Z Národního divadla. Činohra”, Květy, 12 (1890), Vol. II, p. 120.
} 
for Emanuel Bozděch was influenced by his mysterious vanishing-here she expressed herself with a certain piety. According to her Generál bez vojska [The General without an Army] was the best (Zlatá Praha 11 October 1889); other plays were weaker. Later on she compared Bozděch to Victorien Sardou: in her opinion they were different but both were empty in the same way (Zlatá Praha 20 April 1894).

From contemporary playwrights she regarded Jaroslav Vrchlický highly, his trilogy Hippodamie in particular-she considered this as the work of extraordinary qualities. At the same time her concern for Fibich's music did its bit: according to her the melodrama Námluvy Pelopovy [The Courtship of Pelops] by Vrchlický and Fibich meant an "epochmaking act in Czech literature; it was the best, the most perfect connection between music and poetry." ${ }^{16}$ She expressed positive thoughts on other plays by Vrchlický as well, even those characterised by too much lyrism, such as Troji polibení [Three Kisses], (Zlatá Praha 21 October 1892). On the other hand she was critical of Vrchlický-in her review of Midasovy uši [The Midas' Ears] in the journal Zlatá Praha she praised the play with the remark that it was not worth dissecting such a genre (Zlatá Praha 11 November 1892); however, at the same time in the journal Květy she pointed out that the allegorical meaning of the play was not expressed clearly because a spectator reveals this fact at the end of the play (Květy 1 November 1890). Similarly she commented on the play Pietro Aretino-according to her it was not a drama in its real meaning but more likely a kind of dramatic profile. The main character was not a dramatic type, such as Molière's characters (Zlatá Praha 6 May 1892). However, on the occasion of Vrchlický's $40^{\text {th }}$ birthday Schulzová enthusiastically praised him and indirectly defended him against the objections of realistic critics (Zlatá Praha 15 February 1893).

Schulzová was more critical towards Zeyer, Vrchlický's companion from the journal Lumir. She devoted two reviews to his play Sulamit, and she agreed with the opinions of others that this play lacked dramatic effect and that was why it lost its vividness (Zlatá Praha 15 March 1889, Květy 1 May 1889).

Schulzová was rather reserved towards realism, probably influenced by her father who sharply refused Zola and naturalism and supported the ideal realism of Václav Vlček, who was the editor of the journal Osvěta to which Schulz contributed. ${ }^{17}$ "We think that this word has been misunderstood. Why should realism always mean evil, rudeness, wickedness and the grime of life? Is it not possible to describe beauty, nobility, good and great characters realistically?" 18

She regarded Ladislav Stroupežnický highly; however, in the obituary she only praised him for his historical dramas; surprisingly she did not mention his play Naši furianti

16 Anežka Schulzová, “Z Národního divadla. Činohra”, Květy, 12 (1890), Vol. I, p. 500.

17 Eliška Krásnohorská, who also contributed to Osvěta, shared similar opinions with Schulz and Schulzová (Eliška Krásnohorská, "Markéta a Jenůfa" [Margaret and Jenůfa], Ženské listy [Women's Leaves], 19 (1891), p. 29-34, 59-62, 71-72).

18 Anežka Schulzová, "Z Národního divadla. [Úvaha o ruském dramatu a realismu vůbec] [A Reflection on Russian Drama and Realism in General] William Shakespeare: Jindřich IV.”, Zlatá Praha, 6 (1888), p. 59. 
and expressed criticism of his contemporary dramas (Václav Hrobčický z Hrobčic [Václav Hrobčický from Hrobčice], Na valdštejnské šachtě [Waldstein's Shaft], Zlatá Praha 19 August 1892).

Schulzová accepted the play Gazdina roba [The Farmer's Mistress] by Gabriela Preissová with mixed feelings: she appreciated her promising talent but at the same time she reproached the technical imperfections which were caused by the author's inexperience and by the plot originally used in the novella (Zlatá Praha 15 November 1889, Květy 1 December 1889). She was more critical of Její pastorkyňa [Her Stepdaugther] which she considered an "aggressive naturalistic bomb".${ }^{19}$ Like other critics ${ }^{20}$ she considered this play greatly influenced by Tolstoy's The Power of Darkness (the motif of the baby's murder) but she lacked moral justification (unlike in Tolstoy's play). She reproached above all the poor psychological depiction of the main characters, Jenůfa and Kostelnička.

She praised the works of Alois Jirásek, especially Vojnarka (Kvèty 1 June 1890, Zlatá Praha 2 and 9 May 1890) and Otec ([The Father], Zlatá Praha 7 December 1894), which she considered to be a masterful realistic depiction. She also appreciated his dramatic joke Kolébka ([The Cradle], Zlatá Praha 18 and 25 December 1891).

Schulzová accepted Maryša [Marysha] by Brethren Mrštíkové sympathetically, and she praised many good scenes, but she criticised the ending because it was not convincingly justified from the psychological point of view. She reproached them for choosing their characters ( similarly to most Czech playwrights) "from such a social class, where the internal life is very simple and trivial and where there are no modern ways of thinking and no modern movements. [...] While anywhere else literature is as dramatic as an amazon that leads the spiritual life and shows new and courageous ways, Czech drama is very still-and its inactivity is not even disturbed by the march of time." ${ }^{21}$

The works of M. A. Šimáček Schulzová accepted with a certain sympathy and she appreciated his talent for observation, although she apprehended his effort to depict characters accurately in Svět malých lidí [The World of Poor Souls] with reservation (Květy 1 January 1891). She appreciated more fully his play Jiný vzduch [Another Wind], no doubt because of its closer approach to her "modern thinking" but even here she reproached him for several things: a trivial plot, a resemblance to Sudermann's Honour and a character of an overly- moralizing cousin Prokop (Zlatá Praha 2 and 9 February 1894). She considered F. X. Svoboda to be a promising talent for Czech drama; she regarded his plays Směry života ([The Ways of Life], Květy 1 April 1892) and Rozklad ([Degeneration], Zlatá Praha 24 February 1893) highly.

Schulzová's theatre critiques represent a relatively compact collection of relevant information about Schulzová herself and above all about a period which was considered as temporary. Schulzová appears as an extraordinarily educated personality with a broad

19 Anežka Schulzová, “Z Národního divadla. Činohra”, Květy, 12 (1890), Vol. II, p. 752.

20 Artur Závodský, Gabriela Preissová (Prague, 1962), p. 138-161.

21 Anežka Schulzová, “Z Národního divadla. Alois a Vilém Mrštíkové: Maryša”, Zlatá Praha, 11 (1894), p. 322-323. 
cultural horizon. She stressed above all the aspect of modernity in plays. Ibsen, Hauptmann and Sudermann were the symbols of modernity for her and she paid them more attention. She liked conversational plays as well, especially French ones, but here she distinguished carefully between tasteful and worthless plays. In Czech drama she pointed out national aspects, originality and modernity (as she had expressed herself when dealing with the guest plays of the National Theatre in Vienna, Zlatá Praha 17 and 24 June 1892), even though in particular reviews she was more benevolent and enthusiastically accepted even tendentious and period plays, e.g. Šubert's Velkostatkář ([The Landowner], Květy 1 January 1891). Her attitude towards naturalism was ambivalent-she refused gratuitous depictions of the darker sides of life. She shared her demands for modernity and her regard for Western literature, Scandinavian in particular, with the younger critical generation. However, unlike the younger generation (including F. X. Šalda) she also respected Vrchlický and other representative figures of the older generation. Her critiques were unjustly forgotten but they represent a very valuable source for drama reception in the period as well as a record of transformations in the discourse of theatre criticism in one of the most tumultuous periods of modern Czech drama.

Translated by Jitka Rejhonová

\section{A bibliography of Anežka Schulzová's literary-criticism work ${ }^{22}$}

\section{A. Criticism}

Květy

"Z Národního divadla. Činohra”, 11 (1889), Nr. 2, p. 250-252. (Sofokles: Antigona. José Echegaray: Světec či blázen.)

“Z Národního divadla. Činohra”, 11 (1889), Nr. 4, p. 502-504. (František Věnceslav Jeřábek: Služebník svého pána. Franz von Schönthan: Cornelius Voss.)

"Z Národního divadla. Činohra”, 11 (1889), Nr. 5, p. 624-629. (Julius Zeyer: Sulamit. Gregor Csiky: Proletáři. Jaroslav Vrchlický: Bratří.)

"Z Národního divadla. Činohra”, 11 (1889), Nr. 6, p. 751-754. (Viktor Krylov: Medvěd námluvčím. Henrik Ibsen: Nora. Eugène Labiche a Marc-Michel: Následky prvního manželství.)

“Z Národního divadla. Činohra”, 11 (1889), Nr. 11, p. 626-630. (Adolf von Wilbrandt: Dcera pana Fabricia. Emil Pohl: Sedm havranů. E. Siraudin: Tři klobouky. Emanuel Bozděch: Generál bez vojska.)

“Z Národního divadla. Činohra”, 11 (1889), Nr. 12, p. 749-753. (Josef Štolba: Závět. Gabriela Preissová: Gazdina roba. Sofokles: Oidipus král.)

22 This data is taken from bibliographical catalogues of the Centre for Information on Literary Studies, the Institute of Czech Literature (Academy of Sciences Czech Republic) in Prague. This register does not contain Anežka Schulzová's artistic works (e.g. libretti) and gives only original names of articles in Czech language. 
“Dramatické umění. Činohra”, 12 (1890), Nr. 2, p. 250-252. (František Herites: Těžké stíny. Victorien Sardou: Dora.)

"Z Národního divadla. Činohra”, 12 (1890), Nr. 3, p. 375-376. (Eugène Labiche a Édouard Martin: Vojanská krev.)

“Z Národního divadla. Činohra”, 12 (1890), Nr. 4, p. 500-504. (Jaroslav Vrchlický: Námluvy Pelopovy. Lope de Vega: Sedlák svým pánem (upr. J. Vrchlický).)

“Z Národního divadla. Činohra”, 12 (1890), Nr. 5, p. 625-627. (Karel Pippich: Slavomam.)

"Z Národního divadla. Činohra”, 12 (1890), Nr. 6, p. 748-752. (Alois Jirásek: Vojnarka. Alexandre Bisson a Antony Mars: Překvapení z rozvodu.)

“Z Národního divadla. Činohra”, 12 (1890), Nr. 7, p. 120-121. (Anton Pavlovič Čechov: Námluvy.)

"Z Národního divadla. Činohra”, 12 (1890), Nr. 10, p. 497-500. (Arthur Wing Pinero: Policejní soudce. Titus Maccius Plautus: Menaechmové.)

“Z Národního divadla. Činohra”, 12 (1890), Nr. 11, p. 628-630. (Jaroslav Vrchlický: Midasovy uši.)

“Z Národního divadla. Činohra”, 12 (1890), p. 12, p. 750-754. (Friedrich Schiller: Loupežníci. Gabriela Preissová: Její pastorkyňa.)

“Z Národního divadla. Činohra”, 13 (1891), Nr. 1, p. 122-125. (Matěj Anastázia Šimáček: Svět malých lidí. František Adolf Šubert: Velkostatkář.)

"Z Národního divadla. Činohra", 13 (1891), Nr. 2, p. 249-252. (Victorien Sardou: Theodora. Pierre Beaumarchais: Figarova svatba.)

“Z Národního divadla. Činohra”, 13 (1891), Nr. 3, p. 371-378. (Hermann Sudermann: Čest.)

"Z Národního divadla. Činohra”, 13 (1891), Nr. 6, p. 750-754. (Henrik Ibsen: Nepřítel lidu.)

“Z Národního divadla”, 13 (1891), Nr. 7, p. 121-126. (Jaroslav Vrchlický: Smír Tantalův.)

"Dramatické umění", 13 (1891), Nr. 10, p. 495-503. (Hermann Sudermann: Konec Sodomy.)

"Z Národního divadla”, 14 (1892), Nr. 1, p. 119-126. (Jaroslav Vrchlický: Smrt Hippodamie.)

"Z Národního divadla”, 14 (1892), Nr. 4, p. 496-504. (František Xaver Svoboda: Směry života. František Ruth: Jindřich Urban.)

“Z Národního divadla. Bjørnsterne Bjørnson: Bankrot”, 15 (1893), Nr. 1, p. 121-126.

“Gerhart Hauptmann a jeho 'Hanička”, 16 (1894), Nr. 4, p. 497-504. (Tkalci, Před slunce východem, Samotáři, Hanička.)

\section{Zlatá Praha}

“Šibřinky. Causerie”, 5 (1887-1888), Nr. 14, p. 222, 24. 2. 1888.

"Dumy a legendy Otakara Mokrého", 5 (1887-1888), Nr. 23, p. 366, 27. 4. 1888.

"Z Národního divadla. František Adolf Šubert: Praktikus”, 5 (1887-1888), Nr. 47, p. 751, 12. 10. 1888.

"Z Národního divadla. Édouard Pailleron: Myška. Moser: Bibliotékáŕ", 6 (1887-1888), Nr. 3, p. $35,7.12 .1888$.

"Z Národního divadla. Ladislav Stroupežnický: Václav Hrobčický z Hrobčic”, 6 (1887-1888), Nr. 4, p. 47, 14. 12. 1888.

"Z Národního divadla. (Úvaha o ruském dramatu a realismu vůbec.) William Shakespeare: Jindřich IV.", 6 (1887-1888), Nr. 5, p. 59-60, 21. 12. 1888.

"Z Národního divadla. William Shakespeare: Sen noci Svatojánské. Karel Ladislav Kukla: Svatební noc", 6 (1888-1889), Nr. 6, p. 72, 28. 12. 1888.

"Z Národního divadla. Jaroslav Vrchlický: Pomsta Catullova. Otto Pinkas: Fotografie. Václav Kliment Klicpera: Rohovín Čtverrohý”, 6 (1888-1889), Nr. 7, p. 83, 4. 1. 1889. 
"Z Národního divadla. Sofokles: Antigona”, 6 (1888-1889), Nr. 9, p. 107-108, 18. 1. 1889.

“Z Národního divadla. José Echegaray, Světec či blázen”, 6 (1888-1889), Nr. 10, p. 120, 25. 1. 1889.

"Z Národního divadla. František Ferdinand Šamberk: Ravuggiollo", 6 (1888-1889), Nr. 11, p. 131-132, 1. 2. 1889 .

"Z Národního divadla. Armand d’Artois: Aféra Clémenceaeova”, 6 (1888-1889), Nr. 14, p. 167-168, 22. 2. 1889 .

"Z Národního divadla. František Věnceslav Jeřábek: Služebník svého pána. Franz von Schönthan: Cornelius Voss", 6 (1888-1889), Nr. 16, p. 192, 8. 3. 1889.

"Z Národního divadla. Franz von Schönthan: Cornelius Voss. Julius Zeyer: Sulamit”, 6 (1888-1889), Nr. 17, p. 203-204, 15. 3. 1889.

“Z Národního divadla. Gregor Csiky: Proletáři”, 6 (1888-1889), Nr. 18, p. 216, 22. 3. 1889; Nr. 19, p. 227-228, 29. 3. 1889.

"Z Národního divadla. Jaroslav Vrchlický: Noc na Karlštejně”, 6 (1888-1889), Nr. 22, p. 264, 19. 4. 1889.

“Z Národního divadla. Jaroslav Vrchlický: Bratři. Viktor Krylov: Medvěd námluvčím”, 6 (1888-1889), Nr. 23, p. 276, 26. 4. 1889; Nr. 24, p. 287, 3. 5. 1889.

"Z Národního divadla. Henrik Ibsen: Nora. Eugène Labiche a Marc-Michel: Následky prvního manželství", 6 (1888-1889), Nr. 25, p. 299-300, 10. 5. 1889; Nr. 26, p. 311, 17. 5. 1889.

"Z Národního divadla. Jules Verne: Cesta kolem světa”, 6 (1888-1889), Nr. 30, p. 359-360, 14. 6. 1889.

"Z Národního divadla. Georges Feydeau: Dámský krejčí, 6 (1888-1889), Nr. 40, p. 480, 23. 8. 1889.

"Z Národního divadla. Adolf von Wilbrandt: Dcera pana Fabricia”, 6 (1888-1889), Nr. 44, p. 528, 20. 9. 1889.

"Z Národního divadla. Emil Pohl: Sedm havranů”, 6 (1888-1889), Nr. 45, p. 540, 27. 9. 1889.

"Z Národního divadla. Siraudin: Tři klobouky", 6 (1888-1889), Nr. 46, p. 551, 4. 10. 1889.

"Z Národního divadla. Emanuel Bozděch: Generál bez vojska”, 6 (1888-1889), Nr. 47, p. 563, 11. 10.1889.

“Z Národního divadla. Josef Štolba: Závět”, 6 (1888-1889), Nr. 49, p. 588, 25. 10. 1889; Nr. 50, p. 599-600, 1. 11. 1889.

“Cizi premiéry. Alphonse Daudet: La lutte pour la vie”, 6 (1888-1889), Nr. 51, p. 612, 8. 11. 1889.

"Z Národního divadla. Gabriela Preissová: Gazdina roba”, 6 (1888-1889), Nr. 52, p. 623-624, 15. 11. 1889.

“Z Národního divadla. Sofokles: Oidip král”, 7 (1889-1890), Nr. 2, p. 23-24, 29. 11. 1889.

"Z Národního divadla. Alfred Duruy a Henry Chivot: Madame Spinetti. Kanajev: Škola pohostinství”, 7 (1889-1890), Nr. 6, p. 72, 27. 12. 1889.

“Z Národního divadla. František Herites: Těžké stíny”, 7 (1889-1890), Nr. 9, p. 107-108, 17. 1. 1890.

"Z Národního divadla. Sardou: Dora”, 7 (1889-1890), Nr. 10, p. 120, 24. 1. 1890.

"Z Národního divadla. Eugène Labiche a Édouard Martin: Vojanská krev", 7 (1890), Nr. 13, p. 156, 14. 2. 1890

"Z Národního divadla. Jaroslav Vrchlický: Námluvy Pelopovy”, 7 (1889-1890), Nr. 15, p. 180, 28. 2. 1890.

"Z Národního divadla. Emanuel Bozděch: Náramek”, 7 (1889-1890), Nr. 17, p. 203-204, 14. 3. 1890.

“Z Národního divadla. Lope de Vega: Sedlák svým pánem”, 7 (1889-1890), Nr. 18, p. 216, 21. 3. 1890.

"Z Národního divadla. Karel Pippich: Slavomam”, 7 (1889-1890), Nr. 22, p. 264, 18. 4. 1890.

“Z Národního divadla. Alois Jirásek: Vojnarka”, 7 (1889-1890), Nr. 24, p. 287-288, 2. 5. 1890; Nr. 25, p. 298-299, 9. 5. 1890.

"Z Národního divadla. Alexandre Bisson a Antony Mars: Překvapení z rozvodu”, 7 (1889-1890), Nr. 25, p. 298-299, 9. 5. 1890. 
“Z Národního divadla. Alexandre Dumas ml.: Levoboček”, 7 (1889-1890), Nr. 28, p. 335, 30. 5. 1890.

"Z Národního divadla. Franz von Schönthan a Gustav Kadelburg: Zlaté rybky”, 7 (1889-1890), Nr. 32, p. 383, 27. 6. 1890.

"Z Národního divadla. Ferdinand Laloue, Anicet Bourgeois a Laurent: D́áblovy pilulky”, 7 (1889-1890), Nr. 36, p. 430-432, 25. 7. 1890.

"Z Národního divadla. Labiche a Martin: Dobrodiní souži”, 7 (1889-1890), Nr. 37, p. 443-444, 1. 8. 1890.

"Z Národního divadla. Charlotte Birch-Pfeifferová: Sirotek Lovoodský”, 7 (1889-1890), Nr. 42, p. 504, 5. 9. 1890.

“Z Národního divadla. Arthur Wing Pinero: Policejní soudce”, 7 (1889-1890), Nr. 44, p. 527-528, 19. 9.1890.

“Z Národního divadla. Titus Maccius Plautus: Menaechmové”, 7 (1889-1890), Nr. 47, p. 563, 10. 10. 1890.

"Z Národního divadla. Jaroslav Vrchlický: Midasovy uši”, 7 (1889-1890), Nr. 48, p. 576, 17. 10. 1890.

"Z Národního divadla. Friedrich Schiller: Loupežníci”, 7 (1889-1890), Nr. 50, p. 600, 31. 10. 1890.

"Z Národního divadla. Gabriela Preissová: Její pastorkyňa", 7 (1889-1890), Nr. 52, p. 624, 14. 11. 1890.

“Z Národního divadla. Sen v (!) noci Svatojánské”, 8 (1890-1891), Nr. 6, p. 72, 26. 12. 1890.

"Z Národního divadla. Slečna Ludmila Vlčková a Welsová (Posouzení hereckého výkonu)", 8 (1890-1891), Nr. 7, p. 84, 2. 1. 1891.

"Z Národního divadla. Victorien Sardou: Theodora”, 8 (1890-1891), Nr. 9, p. 108, 16. 1. 1891.

"Z Národního divadla. Pierre Beaumarchais: Figarova svatba”, 8 (1890-1891), Nr. 10, p. 120, 23. 1. 1891.

"Z Národního divadla. Hermann Sudermann: Čest. Molière: Lakomec”, 8 (1890-1891), Nr. 12, p. $143-144,6.2 .1891$.

“Z Národního divadla. Jaroslav Vrchlický: Námluvy Pelopovy”, 8 (1890-1891), Nr. 13, p. 156, 13. 2. 1891.

“Z Národního divadla. Petr Michajlovič Nevežin: Druhá mladost”, 8 (1890-1891), Nr. 15, p. 180, 27. 2. 1891.

“Z Národního divadla. Josef Štolba: Křivé cesty”, 8 (1890-1891), Nr. 17, p. 204, 13. 3. 1891.

"Z Národního divadla. Emanuel Bozděch: Spoutaní, 8 (1890-1891), Nr. 19, p. 227-228, 27. 3. 1891.

"Z Národního divadla. Friedrich Schiller: Marie Stuartovna”, 8 (1890-1891), Nr. 21, p. 252, 10. 4.1891.

"Z Národního divadla. Eugène Scribe a Ernest Legouvé: Adrienna Lecouvreurová”, 8 (1890-1891), Nr. 22, p. 263-264, 17. 4. 1891.

"Z Národního divadla. William Shakespeare: Mnoho povyku pro nic. (Mordzejewská - herecký výkon.)”, 8 (1890-1891), Nr. 23, p. 276, 24. 4. 1891.

“Z Národního divadla. Henrik Ibsen: Nepř́tel lidu”, 8 (1890-1891), Nr. 27, p. 324, 22. 5. 1891.

"Liduška Danzerová. (Charakteristika herecké indidividuality.)", 8 (1890-1891), Nr. 29, p. 347-348, 5. 6. 1891.

"Z Národního divadla. Jaroslav Vrchlický: Smír Tantalův”, 8 (1890-1891), Nr. 30, p. 358 and 360, 12. 6. 1891.

“Z Národního divadla. Jaroslav Vrchlický: Smír Tantalův”, 8 (1890-1891), Nr. 31, p. 372, 19. 6. 1891.

"Z Národního divadla. Victorien Sardou: Thermidor", 8 (1890-1891), Nr. 32, p. 384, 26. 6. 1891.

"Z Národního divadla. Michel Carré ml.: Drama beze slov", 8 (1890-1891), Nr. 45, p. 539-540, 25. 9. 1891.

“Z Národního divadla. Josef Kajetán Tyl: Měštané a studentíci aneb Dobývání Prahy od Švédů”, 8 (1890-1891), Nr. 46, p. 552, 2. 10. 1891. 
“Z Národního divadla. Nikolaj Vasiljevič Gogol: Revisor”, 8 (1890-1891), Nr. 50, p. 600, 30. 10. 1891.

"Z Národního divadla. Jaroslav Vrchlický: Smrt Hippodamie”, 8 (1890-1891), Nr. 52, p. 623-624,

12. 11. 1891.

"Z Národního divadla. Jaroslav Vrchlický: Smrt Hippodamie", 9 (1891-1892), Nr. 1, p. 10, 20. 11. 1891.

“Z Národního divadla. George Ohnet: Majitel hutí, 9 (1891-1892), Nr. 2, p. 22, 27. 11. 1891.

"Z Národního divadla. Václav Vlček: Povodeň”, 9 (1891-1892), Nr. 3, p. 36, 4. 12. 1891.

“Z Národního divadla. Édouard Pailleron: Myška”, 9 (1891-1892), Nr. 4, p. 47, 11. 12. 1891.

"Z Národního divadla. Alois Jirásek: Kolébka”, 9 (1891-1892), Nr. 5, p. 60, 18. 12. 1891; Nr. 6, p. 71-72, 25. 12. 1891.

"Z Národního divadla. Johann Wolfgang Goethe: Egmont”, 9 (1891-1892), Nr. 9, p. 106-107, 15. 1. 1892.

“Z Národního divadla. František Věnceslav Jeřábek: Cesty veřejného mínění”, 9 (1891-1892), Nr. 10, p. 119-120, 22. 1. 1892.

“Z Národního divadla. William Shakespeare: Pohádka zimního večera”, 9 (1891-1892), Nr. 12, p. $143,5.2 .1892$.

"Z Národního divadla. František Xaver Svoboda: Směry života”, 9 (1891-1892), Nr. 13, p. 154-155, 12. 2. 1892.

“Z Národního divadla. Pohostinské hry Coquelinovy”, 9 (1891-1892), Nr. 15, p. 179-180, 26. 2. 1892.

"Z Národního divadla. Gustav Freytag: Žurnalisté”, 9 (1891-1892), Nr. 15, p. 180, 26. 2. 1892.

"Z Národního divadla. František Ruth: Jindřich Urban. Drama pražského života", 9 (1891-1892), Nr. 17, p. 202-204, 11. 3. 1892.

"Z Národního divadla. Oskar Blumenthal a Gustav Kadelburg: Praha je Praha”, 9 (1891-1892), Nr. 21, p. 251, 8. 4. 1892.

"Z Národního divadla. Jaroslav Vrchlický: Pietro Aretino”, 9 (1891-1892), Nr. 25, p. 298-300, 6. 5. 1892.

"Z Národního divadla. Pohostinské hry Národního divadla na výstavě Vídeňské”, 9 (1891-1892), Nr. 31, p. 371-372, 17. 6. 1892; Nr. 32, p. 382, 24. 6. 1892.

“Z Národního divadla. Alexandre Bisson: Toupinel”, 9 (1891-1892), Nr. 33, p. 395, 1. 7. 1892.

"Z Národního divadla. Malé, př́větivé jeviště arény Švandovy... (Victorien Sardou: Cypriena.)”, 9 (1891-1892), Nr. 33, p. 395, 1. 7. 1892.

“Ladislav Stroupežnický. Nekrolog”, 9 (1891-1892), Nr. 40, p. 471, 19. 8. 1892.

“Z Národního divadla. Lope de Vega: Sedlák svým pánem”, 9 (1891-1892), Nr. 45, p. 540, 23. 9. 1892.

"Z Národního divadla. První dramatický pokus... (Josefina Hellerová - herečka.)”, 9 (1891-1892), Nr. 46, p. 551, 30. 9. 1892.

"Z Národního divadla. Victorien Sardou: Andrea”, 9 (1891-1892), Nr. 48, p. 574-575, 14. 10. 1892.

"Z Národního divadla. Jaroslav Vrchlický: Trojí políbení", 9 (1891-1892), Nr. 49, p. 587, 21. 10. 1892.

"Sen v (!) noci Svatojanské”, 9 (1891-1892), Nr. 50, p. 599, 28. 10. 1892.

"Z Národního divadla. Bjørnsterne Bjørnson: Bankrot”, 9 (1891-1892), Nr. 52, p. 623-624, 11. 11. 1892.

"Z Národního divadla. Reprisa Kupce benátského (William Shakespeare)”, 10 (1892-1893), Nr. 2, p. 22, 25. 11. 1892.

“Z Národního divadla. Václav Kliment Klicpera: Hadrián z Ř́msů”, 10 (1892-1893), Nr. 3, p. 33, 2. 12. 1892.

"Z Národního divadla. G. Rovetta: Pohořel. František Ferdinand Šamberk: Jedenácté přikázání”, 10 (1892-1893), Nr. 4, p. 46, 9. 12. 1892. 
"Z Národního divadla. Ladislav Stroupežnický: Na valdštejnské šachtě”, 10 (1892-1893), Nr. 5, p. $58,16.12 .1892$.

“Z Národního divadla. Reprisa Soudu lásky (Jaroslav Vrchlický)”, 10 (1892-1893), Nr. 8, p. 95, 6. 1.1893.

"Z Národního divadla. Octave Gastineau: Plesové střevíce”, 10 (1892-1893), Nr. 9, p. 108, 13. 1. 1893.

"Z Národního divadla. Emil Pohl: Vasantasena. Přel. Jaroslav Vrchlický”, 10 (1892-1893), Nr. 11, p. 131-132, 27. 1. 1893; Nr. 12, p. 143, 3. 2. 1893.

“Z Národního divadla. (Chvála a obrana Vrchlického)”, 10 (1892-1893), Nr. 13 and 14, p. 159, 15. 2. 1893.

“Z Národního divadla. Jaroslav Vrchlický: Hippodamie. František Xaver Svoboda: Rozklad”, 10 (1892-1893), Nr. 15, p. 179-180, 24. 2. 1893.

“Z Národního divadla. José Echegaray: Velký Galeoto”, 10 (1892-1893), Nr. 17, p. 203-204, 10. 3. 1893.

“Z Národního divadla. Carlo Goldoni: Paní hostinská. Přel. Jaroslav Vrchlický”, 10 (1892-1893), Nr. 21, p. 252, 7. 4. 1893.

"Karel Leger: Slepý", 10 (1892-1893), Nr. 21, p. 252, 7. 4. 1893.

“Z Národního divadla. Franz von Schönthan a Gustav Kadelburg: Dva štastné dny”, 10 (1892-1893), Nr. 23, p. 276, 21. 4. 1893.

“Z Národního divadla. Reprisa Cavallotiho Dcery Joftovy”, 10 (1892-1893), Nr. 24, p. 288, 28. 4. 1893.

"Z Národního divadla. František Ruth: Písmákova dcera”, 10 (1892-1893), Nr. 26, p. 312, 12. 5. 1893.

"Z Národního divadla. Xaver Menhardt: Ve stínu guillotiny”, 10 (1892-1893), Nr. 28, p. 334, 26. 5. 1893.

"Z Národního divadla. Hermann Sudermann: Domov", 10 (1892-1893), Nr. 29, p. 347, 2. 6. 1893.

"Z Národního divadla. Oskar Blumenthal a Gustav Kadelburg: Cesta na východ”, 10 (1892-1893), Nr. 33, p. 396, 30.6. 1893.

“Z Národního divadla. Corneille: Cid”, 10 (1892-1893), Nr. 45, p. 539-540, 22. 9. 1893.

“Z Národního divadla. Feuillet: Bílý vlas”, 10 (1892-1893), Nr. 47, p. 562, 6. 10. 1893.

“Z Národního divadla. Emile Augier: Fourchambaultové”, 11 (1893-1894), Nr. 6, p. 71-72, 21. 12. 1893.

“Z Národního divadla. Reprisa Rabínské moudrosti (Jaroslav Vrchlický)”, 11 (1893-1894), Nr. 8, p. 94, 5. 1. 1894.

"Z Národního divadla. Reprisa Sardouovy Cyprienny”, 11 (1893-1894), Nr. 10, p. 120, 19. 1. 1894.

"Z Národního divadla. Matěj Anastázia Šimáček: Jiný vzduch”, 11 (1893-1894), Nr. 12, p. 141-142, 2. 2. 1894; č. 13, 154, 9. 2.1894.

"Z Národního divadla. Gerhart Hauptmann: Hanička”, 11 (1893-1894), Nr. 15, p. 178-179, 23. 2.1894.

"Z Národního divadla. José Echegaray: Mariana”, 11 (1893-1894), Nr. 20, p. 238-239, 30. 3. 1894.

"Z Národního divadla. Emil Pohl: Krasojezdkyně”, 11 (1893-1894), Nr. 21, p. 252, 6. 4. 1894.

"Z Národního divadla. Victorien Sardou: Madame Sans-Gêne”, 11 (1893-1894), Nr. 23, p. 276, 20. 4. 1894.

“Z Národního divadla. E. J. Pražský: Soirée pana Záhorského”, 11 (1893-1894), Nr. 25, p. 299, 4. 5. 1894.

“Z Národního divadla. Alois a Vilém Mrštíkové: Maryša”, 11 (1893-1894), Nr. 27, p. 322-323, 18. 5. 1894. 
“Z Národního divadla. Ludwig Fulda: Talisman”, 11 (1893-1894), Nr. 29, p. 346, 1. 6. 1894.

"Z Národního divadla. Thomas Brandon: Charleyova teta", 11 (1893-1894), Nr. 39, p. 468, 10. 8. 1894. "Z Národního divadla. Leon Gondillot: Pan podprefekt", 11 (1893-1894), Nr. 44, p. 528, 14. 9. 1894. "Z Národního divadla. František Ruth: První klient”, 11 (1893-1894), Nr. 46, p. 552, 28. 9. 1894. "Z Národního divadla. Ludovic Halévy: Frou-Frou”, 11 (1893-1894), Nr. 48, p. 574-575, 12. 10. 1894. "Z Národního divadla. Édouard Pailleron: Komedianti”, 11 (1893-1894), Nr. 52, p. 622, 9. 11. 1894. “Z Národního divadla. Alois Jirásek: Otec”, 12 (1894-1895), Nr. 4, p. 46-47, 7. 12.1894.

"Z Národního divadla. Alexandre Bisson a Albert Carré: Reduta”, 12 (1894-1895), Nr. 13, p. 156, 8. 2. 1895 .

“Z Národního divadla. Jaroslav Vrchlický: Svědek”, 12 (1894-1895), Nr. 15, p. 180, 22. 2. 1895.

"Z Národního divadla. Josef Jaroslav Kolár: Monika”, 12 (1894-1895), Nr. 19, p. 226, 2. 3. 1895.

\section{B. Studies}

“August Strindberg: Literární silhouetta”, Zlatá Praha, 11 (1893-1894), Nr. 41, p. 483-484 and 486, 24/8, 1894; Nr. 42, p. 495 and 498, 31/8; Nr. 43, p. 510-511, 7/9.

"Anatole France. Literární silhouetta", Zlatá Praha, 12 (1894-1895), Nr. 1, 3 and 6, 16. 11. 1894; Nr. 2, p. 15 and 18, 23. 11. 1894; Nr. 3, p. 31-32 and 34, 30. 11. 1894; Nr. 4, p. 39 and 42, 7. 12. 1894; Nr. 5, p. 55, 14. 12. 1894; Nr. 6, p. 68 and 70, 21. 12. 1894; Nr. 7, p. 78, 28. 12. 1894. "Anatole France. Literární silhouetta”, Květy, 19 (1897), Nr. 52-60.

"Paní Bovaryová a Anna Karenina. Literární causerie”, Květy, 25 (1903), Nr. 7, p. 35-49; Nr. 8, p. 165-178; Nr. 9, p. 351-363; Nr. 10, p. 432-439; Nr. 11, p. 571-592.

“Žena v dílech M. Gorkého. Esej”, Nová česká revue, 1 (1903-1904), Nr. 9, p. 642-662, 15. 6. 1904.

\section{Translations}

1. In books

Édouard Rod, Obětovaná (Knihovna Zlaté Prahy, Vol. 1, $1^{\text {st }}$ Edition, Prague, Jan Otto 1893), 228 p. Georg Brandes, Hlavní proudy literatury století devatenáctého. Romantická škola ve Francii ( $1^{\text {st }}$ Edition, Prague, Jan Otto 1894), 515 p.

Édouard Rod, Z novel Eduarda Roda (Knihovna Zlaté Prahy, Vol. 15, $1^{\text {st }}$ Edition, Prague, Jan Otto 1897), $340 \mathrm{p}$.

Brandes, Georg, Sören Kierkegaard (Kritická knihovna, Vol. 22., $1^{\text {st }}$ Edition, Prague, Josef Pelcl 1904), $240 \mathrm{p}$.

\section{In journals}

“John Milton. Studie literární. Napsal lord Macaulay”, Zlatá Praha, 7 (1889-1890), Nr. 47, p. 561-562, 10. 10. 1890; Nr. 48, p. 574, 17. 10. 1890; Nr. 49, p. 584-587, 24. 10. 1890; Nr. 50, p. 591-594, 31. 10. 1890; Nr. 51, p. 603, 7. 11.1890 (mj. podrobné srovnání Miltonova Ztraceného ráje a Danteovy Božské komedie). 
"Jiř́ Brandes: Henrik Ibsen: Literární studie”, Zlatá Praha, 9 (1891-1892), Nr. 15, p. 175-176 and 178, 26. 2. 1892; Nr. 16, p. 187, 4. 3. 1892; Nr. 17, p. 199-200 and 202, 11. 3. 1892; Nr. 18, p. 211-212 and 214, 18. 3. 1892; Nr. 19, p. 223-225, 25. 3. 1892; Nr. 20, p. 231 and 234, 1. 4. 1892 ; Nr. 21, p. 248-250, 8. 4.1892.

"Jiří Brandes: Gustav Flaubert. Literární studie”, Zlatá Praha, 9 (1891-1892), Nr. 27, p. 315-316 and $318,20.5$. 1892; Nr. 28, p. 331-332 and 334, 27. 5. 1892; Nr. 29, p. 342-343, 3. 6. 1892; Nr. 30, p. 354-355, 10. 6. 1892; Nr. 31, p. 366-367, 17. 6. 1892; Nr. 32, p. 378-379, 24. 6. 1892; Nr. 33, p. 390-392, 1. 7. 1892.

"Edmund a Jules Goncourtové. Literární studie”, Květy, 14 (1892), Nr. 10, p. 493-498; Nr. 11, p. 599-609.

“Jiří Brandes v Praze”, Květy, 15 (1893), Nr. 2, p. 246-252.

"Jiří Brandes: Z Hlavních proudův literatury století XIX. Díl V. Romantická škola ve Francii”, Zlatá Praha 10 (1892-1893), Nr. 17, p. 195-196 and 198, 10. 3. 1893; Nr. 18, p. 207 and 210, 17. 3. 1893 ; Nr. 19 , p. $222-223$, 24. 3. 1893; Nr. 20, p. 234-235, 31. 3. 1893; Nr. 21, p. 246, 7. 4. 1893; Nr. 22, p. 258-259, 14. 4. 1893; Nr. 23, p. 268-270, 21. 4. 1893.

“Anatole France: Správce Judska”, Květy, 15 (1893), Nr. 7, p. 105-110.

"Anatole France: Kejkliř Panny Marie”, Národní listy, 33 (1893), Nr. 328, Supp. p. 2, 26. 11. 1893.

"Anatole France: Baltasar", Květy, 15 (1893), Nr. 12, p. 708-716.

"Jiří Brandes: Zviŕ̌ v člověku. Bourget, Maupassant, Dumas, Tolstoj, H. Hart, Zola", Zlatá Praha, 11 (1893-1894, Nr. 3, p. 31-32 and 34, 1. 12. 1893; Nr. 4, p. 39, 8. 12. 1894; Nr. 5, p. 51 and 54, 15. 12. 1894; Nr. 6, p. 66, 22. 12. 1894.

"Jiří Brandes: Emile Zola. Skutečnost a temperament”, Květy, 16 (1894), Nr. 2, p. 216-220; Nr. 3, p. 325-336.

"Jiř́ Brandes: Bedřich Nietzsche. Pojednání o aristokratickém radikalismu”, Zlatá Praha, 11 (1893-1894), Nr. 16, p. 187, 2. 3. 1894; Nr. 17, p. 202-203, 9. 3. 1894; Nr. 18, p. 211-212 and 214, 16. 3. 1894; Nr. 19, p. 223 and 226, 23. 3. 1894; Nr. 20, p. 235, 30. 3. 1894; Nr. 21, p. 246-247, 6. 4. 1894; Nr. 22, p. 262, 263, 13. 4. 1894; Nr. 23, p. 271-272, 20. 4. 1894; Nr. 25, p. 291-292 and 294, 4. 5. 1894.

"Jules Lemaitre: Sérénus. Příběh mučenníka. Povídka”, Zlatá Praha, 11 (1893-1894), Nr. 46, p. 548 and 551-552, 28. 9. 1894; Nr. 47, p. 560-562, 5. 10. 1894; Nr. 48, p. 57, 12. 10. 1894; Nr. 49, p. 582-583, 19. 10. 1894; Nr. 50, p. 591-592 and 594, 26. 10. 1894.

"Jiří Brandes: Lord Byron. Studie”, Zlatá Praha, 12 (1894-1895), Nr. 25, p. 291-292 and 294, 3. 5. 1895; Nr. 26, p. 302-303, 10. 5. 1896; Nr. 27, p. 318-319, 17. 5. 1895; Nr. 28, p. 330-331, 24. 5. 1895 ; Nr. 29 , p. 339 and 342 , 31. 5. 1895 ; Nr. 30, p. 354-355, 7. 6. 1895; Nr. 31, p. 363 and 366, 14. 6. 1895; Nr. 32, p. 380, 21. 6. 1895; Nr. 33, p. 387-390, 28. 6. 1895; Nr. 34, p. $402-403$, 5. 7. 1895 ; Nr. 35 , p. $411-412$ and 414 , 12. 7. 1895 ; Nr. 36 , p. $423-424$ and 426 , 19. 7. 1895 ; Nr. 37 , p. $435-436$ and 438 , 26. 7. 1895 ; Nr. 38 , p. $447-448$ and 450 , 2. 8. 1895 ; Nr. 39, p. 462-463, 9. 8. 1895.

"Anatole France: Jokasta", Zlatá Praha, 13 (1895-1896), Nr. 28, p. 327 and 330, 22. 5. 1896; Nr. 29, p. 343-345, 29. 5. 1896; Nr. 30, p. 351-354, 5. 6. 1896; Nr. 31, p. 367-368, 12. 6. 1896; Nr. 32, p. 378-379, 14. 6. 1896; Nr. 33, p. 392-394, 26. 6. 1896; Nr. 34, p. 400 and 402-403, 3. 7. 1896 ; Nr. 35 , p. 414-416, 10. 7. 1896; Nr. 36, p. 423-426, 17. 7. 1896; Nr. 37, p. 438-439, 24. 7. 1896.

"Anatole France: Thais. Povídka”, Květy, 19 (1897), Nr. 1, p. 61-80; Nr. 2, p. 184-205; Nr. 3, p. 334-356; Nr. 4, p. 471-483; Nr. 5, p. 598-612. 


\section{Other}

“Provolání. Vzdělanstvu českému! Zasláno”, Národní listy, 30 (1890), Nr. 172, Supp., p. 3, 24/6 (Výzva k podpoře Minervy, spolupodepsána Anežka Schulzová).

“Sestry české! Provolání”, Národní listy, 31 (1891), Nr. 100, p. 3, 12/4 (Darování praporu studentům, spolupodepsána Anežka Schulzová).

“Zdenko Fibich. Hrst upomínek a intimních rysův”, Květy, 24 (1902), Nr. 6, p. 768-783, Vol. 2, Nr. 7, p. 67-84.

\section{Die literarisch-kritische Tätigkeit von Anežka Schulzová}

\section{Zusammenfassung}

Die von Anežka Schulzová (1868-1905) verfassten Theaterkritiken stellen ein relativ geschlossenes Ganzen dar. Sie sind ein Zeugnis für die Autorin selbst und für ihre Zeit, die die damalige junge Generation - einschließlich Schulzová - als eine Übergangszeit verstanden hat. Die Kritikerin zeigt sich hier als eine ungemein gebildete Persönlichkeit mit breiten kulturellen Kenntnissen, die sich für die Aufführung moderner ausländischer, vor allem aber tschechischer Werke eingesetzt hat. Die Modernität war für sie vorwiegend durch Namen wie Ibsen, Hauptmann oder Sudermann vertreten, weswegen sie diesen auch größere kritische Aufmerksamkeit gewidmet hat. Ein gewisses Verständnis zeigte sie auch für Konversationsstücke, vor allem französischer Provenienz, auch hier hat sie jedoch streng die geschmackvollen von den wertlosen Werken unterschieden. Für das tschechische Drama verlangte sie einen nationalen Akzent, Originalität und Modernität, obwohl sie sich in den konkreten Kritiken an diese Postulate nicht immer gehalten und auch die ausgesprochen tendenziösen und aktuell-bedingten Werke positiv besprochen hat. Sie hatte eine ambivalente Beziehung zum Naturalismus, die Darstellungen der dunklen Seiten des Lebens hat sie als Selbstzweck abgelehnt. Die Forderung nach Modernität und ihre Bewunderung für die zeitgenössische westliche, vor allem skandinavische Literatur, hatte sie mit der jungen Generation der Kritiker gemeinsam. Eine zu diesen unterschiedliche Meinung hatte sie über die Theaterautoren der älteren Generation und über die Theaterstücke von Jaroslav Vrchlický, den sie geschätzt hat, während die jungen Kritiker mit František Xaver Šalda an der Spitze ihn scharf attackiert haben. Die mit Unrecht in Vergessenheit geratenen Kritiken von Anežka Schulzová stellen ein sehr wichtiges Dokument zur damaligen Rezeption des dramatischen Schaffens dar; sie sind auch ein Beleg für die Änderungen in den Ansichten der Theaterkritik in einer der stürmischsten Zeiten des modernen tschechischen Dramas. 


\title{
Literárněkritická činnost Anežky Schulzové
}

\begin{abstract}
Shrnutí
Divadelní kritiky Anežky Schulzové (1868-1905) představují relativně ucelený soubor, který dobře vypovídá o jejich autorce i o době, kterou zejména mladá generace Schulzovou nevyjímaje - vnímala jako dobu přechodnou. Kritička v nich vystupuje jako nevšedně vzdělaná osobnost se širokým kulturním rozhledem, jež klade důraz především na modernost cizích a zejména českých děl. Modernost pro ni symbolizovala především jména jako Ibsen, Hauptmann či Sudermann, jimž věnovala zvýšenou kritickou pozornost. Jisté pochopení ale měla i pro konverzační drama, zejména francouzské, i zde však př́isně rozlišovala díla vkusná a bezcenná. V českém dramatu kladla velký důraz na národnost, původnost a modernost, i když v konkrétních kritikách se těchto postulátů mnohdy nedržela a dokázala nadšeně přijmout i díla vysloveně dobová a tendenční. Její vztah k naturalismu byl poněkud ambivalentní, odmítala zejména samoúčelnost v zobrazování temných stránek života. S mladou kritickou generací devadesátých let ji spojovala myšlenka modernosti a obdiv k současným západním, zejména severským literaturám. Rozcházela se s ní zejména v respektu k divadelním hrám Jaroslava Vrchlického, na něhož tato generace v čele s F. X. Šaldou ostře útočila, i v úctě a pochopení pro autory starších ročníků. Její neprávem zapomenuté kritiky tak tvoří velmi cenný dokument dobové recepce dramatické tvorby i doklad proměn diskurzu divadelní kritiky v jednom z nejbouřlivějších období moderního českého dramatu.
\end{abstract}

\section{Keywords}

Anežka Schulzová; Czech theatre criticism around 1900. 